\title{
AC 2011-1735: DEVELOPMENT OF ENGINEERING ETHICS COURSE
}

\section{Diana Bairaktarova, Purdue University, West Lafayette}

Diana Bairaktorova is a PhD student in the School of Engineering Education at Purdue University. She hold BS and MS in Mechanical Engineering from Technical University of Sofia, Bulgaria and an MBA from Hamline University, St. Paul, Minnesota. She has 7 years of professional experience, working as a Module Design and MMIC Test Engineer at TLC Precision Wafer Technology in Minneapolis, MN and as an Operations Engineer at Napco International in Hopkins, MN.

\section{Demetra Evangelou, Purdue University, West Lafayette}

Dr. Demetra Evangelou is Assistant Professor of Engineering Education in the School of Engineering Education at Purdue University. She has a PhD in Early Childhood Education from the University of Illinois at Urbana-Champaign and international expertise in early childhood policy and research methods. Her current research focuses on developmental engineering, early education antecedents of engineering thinking, developmental factors in engineering pedagogy, technological literacy and human-artifact interactions. She is a member of Sigma Xi Science Honor Society and in 2009 he was awarded the prestigious NSF CAREER Award. 


\section{Development of an Engineering Ethics Course}

\section{Introduction}

Criterion three of ABET's Engineering Criteria 2000 requires engineering programs to demonstrate that their graduates have "an understanding of professional and ethical responsibility"1. The field of engineering ethics examines and sets standards for engineers' obligations to the public, their clients, employees and the profession. ${ }^{2}$ In the course of practicing engineering, an engineer solves problems. The engineering decisions are generally guided by the project management variables of cost, schedule and quality. But engineering decisions are also guided by moral values; concern and respect for others. Gaul Baura in "Engineering Ethics" states: "The corporate culture is very powerful and can sway a young engineer's thinking". 3 As Baura continues: "In preparation for being involved in unethical situations you cannot control, it is important to know your limits. Know your personal engineering ethics threshold for action.",3 This paper proposes an engineering ethics course that will help students develop these personal engineering ethics and presents the outline of the content, assessment, and pedagogy for teaching the Engineering Ethics course.

As part of the course modules for ethics communications and group work projects have been developed. The paper starts with a background outlining the context of the Engineering Ethics course, mentions some particular so called "best practices" to present such a course, explores assumptions about the course audience and raises some possible bottlenecks in teaching engineering ethics. It then continues with an overview of the content, assessment, and pedagogy, including my pedagogical approach to teaching this course. Finally, the alignment of these three areas closes out the document. For a better understanding of the course design, supportive materials such as the course syllabus, assessment worksheet, assessment triangle for resolution of ethical dilemmas, and a course schedule are integrated into the text.

\section{A note to the reader}

The motivation to create this course comes from years of personal experience practicing engineering and encountering issues of unethical practice that often arose in the workplace. These experiences have led to my belief that students graduating from engineering programs must have an understanding of how ethics work in the real world and how ethical problems can affect an engineer's entire professional career. This course will focus on the ethics of engineering practice. As part of the course students will be expected to consider the effects of their actions (and failure to act) including the economic, environmental, political, societal, health and safety consequences of their work, while also keeping in mind the manufacturability and sustainability of their structures and products.

This course was originally developed in the context of a curriculum design course. It was created with the intention of further development using the results of a program of rigorous research to evaluate the assessment tool and understand how engineering students acquire moral reasoning. A further effort was intended to identify ways through which the course could easily be incorporated into the wider curriculum. This paper includes my personal pedagogical philosophy, in addition to discussions of course content and other course details, in order to help the reader understand the approach taken to teaching engineering ethics and how it differs from traditional methods. This paper has been shared with experts in the engineering ethics field for 
review and feedback on the course content and assessment tool and this feedback will be presented at the ASEE conference in June 2011 and published in a future paper.

\section{Background}

In the 1920s, less than a third of engineering educators considered the study of differential equations to be necessary for an engineer's education, now such study is integral to the engineering curriculum. In the engineering world of the future, a sound understanding of the theoretical and practical sides of engineering ethics will be as necessary to the proper education of engineers as a knowledge of differential equations is today, if not more so".

Robin Tatu in her article "Knowledge Isn't Enough" takes the famous quote from the Greek inventor Archimedes "Give me a place to stand and I will move the Earth" and argues that "the potential to wield such power is accompanied by equally weighty social responsibility, however; and today, that obligation is becoming ever more pressing and complex". As Tatu continues in discussing the new book written by Douglas, Papadopoulos, and Boutelle "Citizen Engineer" : "A successful $21^{\text {st }}$ century engineer must become "part environmentalist, part intellectual property attorney, part MBA, and part diplomat - not to mention an expert in an engineering discipline, a great teammate, and a skilled communicator". 5 This view is supported by the National Academy of Engineering as suggested in Educating the Engineer of 2020:

"Within the context of the changing national and global landscape, The US National Academy of Engineers enunciated a set of aspirations for engineers in 2020. The future engineers have to be technically proficient engineers who are broadly educated, see themselves as global citizens, can be leaders in business and public service, and who are ethically grounded. The committee set targeting attributes needed for the graduates of 2020. These include such traits as strong analytical skills, creativity, ingenuity, professionalism, and leadership". ${ }^{6}$

As of today, even though Criterion three of ABET's Engineering Criteria 2000 requires engineering programs to demonstrate that their graduates have an understanding of professional and ethical responsibility, the teaching of engineering ethics is still not a high priority in U.S. engineering education. This is partly because engineering faculty do not accept enough responsibility for the teaching of engineering ethics. ${ }^{7}$ Engineering ethics courses are not mandatory and when offered through engineering schools are integrated through the curriculum in a variety of different forms. While the methods of ethics instruction and assessment are often left to the discretion of the instructor, methods of curricular incorporation are mostly established at the institutional level. The predominant methods of curriculum incorporation include: required courses within the discipline, elective courses outside the discipline, across-the-curriculum, and the linking of ethics with society. ${ }^{8}$ As Ohland and Barry state: "applied ethics plays a critical role in engineering, health, business, and law. Applied ethics is currently a required component of the pre-practice education for these professions, yet the literature suggests that challenges remain in how we define, instruct, and assess professions-based ethics education." "Without clear evidence, the debate over curriculum methods will continue, and the engineering community cannot advance its approach to this important subject". 7 


\section{Course Development}

The initial intent was to design a course in engineering ethics with an across-the-curriculum approach. This approach exposes students to ethical considerations repetitively, in multiple courses, during a progression towards their degree. The method requires a commitment among all department faculty to capitalize on ethics discussions within traditional non-ethics focused courses. ${ }^{9}$ However, after exploring one such across-the-curriculum setting where students had only three sections of forty-five minutes through the whole semester and discussing this approach with the teaching professor who shared that his biggest issue in teaching ethics acrossthe curriculum is the lack of time, this course in engineering ethics was changed to fit within the program. In this approach an ethics course is conducted as a full-semester, multiple-credit class, that all students are required to complete. This model allows the class content to focus on discipline-specific issues. ${ }^{10}$ Cooper (1955) and later Drake (2005) performed a comparison of a stand-alone ethics courses within the engineering curriculum versus across-the-curriculum method. This rare comparison of the two methods was unsuccessful in generating statistics in support of either method. ${ }^{7}$

This proposed three (3) credit hour Engineering Ethics course will be offered to students in engineering programs and will be open to enrollment from all majors to promote interdisciplinary interaction. This setting leads to the following assumptions about the course audience: (1) it will contain a diverse mixture of engineering practice and engineering professional knowledge; (2) it will contain a diversity of moral codes partially as a result of diverse cultural backgrounds; (3) it will have differing levels of experience with critical and analytical thinking.

\section{Bottlenecks}

In the course of teaching engineering ethics a few possible bottlenecks exist. First, it could be difficult to motivate students to take the course seriously as it is not one of the primaries in the engineering curriculum. Students will need to be convinced that the course is intended to encourage genuine moral reflection rather than mere recitation. This bottleneck could be overcome by creating an opportunity to exercise and refine students' critical, moral abilities. If they are invited to reflect on realistic, engaging case studies in ways that respect their moral capabilities, they will sense that they are being respected as moral agents and thinkers in their own right. As M. Pritchard states: "To get students to take the study of ethics seriously, they must be convinced that they are being taken seriously". ${ }^{12}$ In a recent conversation with $\mathrm{Mr}$. Tinus, an ethics instructor in XXXX program at XXXXX University, he validated the words of Pritchard. Mr. Titus stated that "Students want to feel that they are important and are in charge of the situation, they want ownership. As engineering students they like their work to be meaningful, when helping students to develop skills that enable them to solve ethical problems, students are proud that their knowledge is useful". ${ }^{13}$

A second bottleneck is that, in general, students have a difficult time dealing with too much complexity. However, the real world is complex, dynamic, and not transparent; this is true in the world of ethics as well as engineering. Complexity is often dealt with by creating models. While models are necessary, it is also necessary that the students understand the differences between models and real life, and the importance of selecting the model that is appropriate for the 
situation. Usually, the cases used as models in teaching engineering ethics are reflections of large ethical problems that arise infrequently in engineering rather than ordinary circumstances. One way to overcome this context bottleneck is if extraordinary cases are limited and the main focus is on cases inspired by real interviews and guest speakers such as professional engineers. When students use their own projects as examples to identify a possible ethical issue and to exercise ethical thinking they are more engaged than when working on cases. "Students like to have ownership. Relative examples from their service-learning design projects are helping students understand that the decision making process in ethics in right way is not different in what they are doing in the design process". 13

\section{Course Overview}

This course is sixteen weeks in length with class sessions once a week. Regular class sessions last for three hours. An outline of the activities that will occur during each class session is provided below. Complete descriptions of the course activities for each session are found in the Course Syllabus section.

\section{Content}

"Content consists of vocabulary, definitions, facts, principles, information, and other concrete and abstract concepts...content is what is written in textbooks, delivered in the lectures, and tested by most basic test formats". ${ }^{14}$ The course of engineering ethics outlined in this paper intends to create an environment that encourages "meaningful learning; learning that is connected to prior knowledge and useful for future performance". ${ }^{14}$ This course uses Wiggins and McTighe's "Establishing Curricular Properties"" 15 framework for exploring content. The course content focuses on three sets of problems:

\section{1). Important dimensions of professional ethics}

\section{2). Primary strategies of ethical argumentations and concepts}

- Philosophical concepts: Utilitarianism, Kantianism, Rawls

- Philosophy of engineering: metaphysics, ethics, epistemology and education

- Problems of ethical sensitivity: principal limits; habits of thinking, stereotypes, group thinking

3). Training in ethical argumentation by means of case studies from engineering, technology, and science:

- Engineering ethics case studies: historical cases taken primarily from scholarly literature

- Discussion and recommended action on hypothetical cases and reflective journals written by students

- Learn from example and by doing: PE guest speakers; presentation of group projects; reflections

This course will focus on helping students to understand the nature and value of "professional and ethical responsibility." In order to develop this understanding, students must be able to communicate their ideas effectively to others, they must explore the effect of engineering solutions in a global and societal context, and they must become familiar with contemporary 
issues both within and beyond the profession of engineering. In addition, by making students aware of the ever-changing nature of engineering ethics, this course will present students with an example of the need for lifelong learning. The course content includes three levels of content: concepts that students should be familiar with, concepts that are important, and concepts about which students should form an enduring understanding.

\section{Worth being familiar with:}

- The nature of engineering ethics - legal, professional, historical and professional definition of Engineering Ethics.

Students should recognize the need for life-long learning and have the skills that will enable them to engage in life-long learning through life experience to handle ethical problems.

\section{Important to know and do:}

- The value of Engineering Ethics - valued contemporary and historical professional reasons why engineers should be ethical.

Students should recognize the non-technical factors in engineering decision making such as diversity in society and social responsibilities that impact infrastructure construction and the ethical conduct of engineering duties.

\section{“Enduring” understanding:}

- Resolution of ethical dilemmas - understanding the grounded philosophical concepts of ethics and using common ethical dilemmas to indentify possible actions to be taken in response, and the probable consequences of those actions.

Students should experience the interdisciplinary nature of engineering projects and be able to effectively collaborate and develop consensus in interdisciplinary teams solving multidisciplinary problems.

The three course concepts are embodied in the course learning objectives listed below. These learning objectives were specifically developed around Fink's approach "A Self-Directed Guide to Designing Courses for Significant Learning". ${ }^{16}$ Fink's approach is an integrated course design that is based on first developing individual components such as identifying situational factors and learning goals, and then integrating the individual components into an overall structured course, and finally planning of student factors such as grading system and course syllabus. Fink offers a taxonomy of significant learning that has a hierarchy which is meaningful in this design context such that knowledge, application, and integration are defined.

\section{Learning objectives in the Engineering Ethics course:}

- Students should recognize ethical issues

- Students should exercise ethical thinking

- Students should apply ethical judgment

The first objective aligns with Fink's Fundamental Knowledge. This objective requires that students gain an understanding of the legal, professional, historical, and personal definitions of 
engineering ethics and be familiar with some ethical concept distinctions such as moral dilemmas, responsibility, whistle blowing, professional ethics vs. personal ethics, utilitarianism, duty, virtue and rights.

The second objective falls into Fink's Integration, Human Dimensions, and Caring goals. Students will learn contemporary and historical legal, professional, and personal reasons why an engineer should be ethical and identify moral dilemmas/challenges and exercise ethical thinking.

The third objective aligns with Fink's Application, Integration, and Learning How to Learn goals, (as well Human Dimensions and Caring again). Here students develop analytical skills in ethics by using common ethical dilemmas to identify possible course of action, the probable consequences of those actions, and the application of ethical judgment. This learning objective stimulates student's ethical imagination and promotes a sense of responsibility.

\section{Assessment}

At the end of the course, students should show a developing sensitivity to identifying ethical issues, have knowledge relevant to ethical issues, improved ethical judgment, and commitment to practicing and promoting ethical behavior in the workplace. While the last cannot be tested, using different assignments such as reflective journals, essays, group exercises, and role playing can help to measure the ability to indentify ethical dilemmas, use ethical imagination and ethical judgment.

Assessment of general moral reasoning has been studied and significantly advanced. Several instruments exist for the purpose of measuring moral reasoning. Several disciplines have developed instruments for measuring the moral reasoning of members of their community. However, while the health and business professions have advanced discipline- specific assessment tools to target professional ethics and found value in the creation of such instruments, engineering does not currently have a similar fully developed assessment tool. ${ }^{11}$ The literature revealed very little published research on the subject of an engineering-based moral reasoning assessment tool. Two conference papers, published in 2003 and 2004, identified this apparent deficiency and discussed research efforts to develop an instrument (Shuman et al., 2004; Sindelar et al., 2003). ${ }^{17}$ Unfortunately, that work remains incomplete and correspondence with the principal investigators indicates no immediate plans to revive the studies . ${ }^{7}$

The framework for most of the modern efforts to assess moral reasoning was developed by Lawrence Kohlberg. Kohlberg believed that individuals progress through a series of six stages of moral reasoning. Kohlberg's field instrument for measuring moral reasoning is known as the Moral Judgment Interview (MJI). The assessment focuses on the justification for the participants' reasoning, rather than the evaluation of correct or incorrect responses. Participants are scored based on the relation between their responses to the dilemmas and Kohlberg's six predefined stages. The MJI has been shown to be a valid and reliable assessment of moral reasoning. ${ }^{11}$

James Pellegrino's Assessment Triangle was used to structure the assessment methods in the engineering ethics course: 
"Reasoning about students' knowledge from evidence obtained in an educational assessment is portrayed as a triad of three interconnected elements - the assessment triangle. The vertices of this triangle represent the three key elements underlying any educational assessment: a model of student cognition and learning in an academic domain; a set of beliefs about the kinds of observations that will provide evidence of students' competencies; and an interpretation process for making sense of the evidence. These three elements may be explicit or implicit, but an assessment cannot be designed and implemented without consideration of each."18

Kohlberg's frame work of stages of moral development was used as a foundation in the cognition part of the course's Assessment Triangle for resolution of ethical dilemmas (see Fig.2 below). The ibservation corner was satisfied using students' ability to identify ethical dilemmas, name possible course of action, and evaluate consequences of actions to provide evidence of students' competence. In the interpretation corner of the triangle, the Pittsburgh-Mines Engineering Ethics Assessment Rubric ${ }^{19}$ serves in the interpretation process for making sense of the evidence. This matrix was developed by a team of researchers from engineering, philosophy, and bioethics from the University of Pittsburgh and the Colorado School of Mines. This rubric was chosen because of its clear outline and as well as for the good reputation of these schools in teaching ethics (See Appendix, Fig.1).

It has been well documented that the methods of assessment used can influence learning in the course and the success of the course objectives. ${ }^{20}$ In order to provide the most accurate assessment for this type of course and also promote learning, there is a need to structure the assessment so that students' development throughout the course could be observed. In the Assessment worksheet (See Appendix, Fig.2) the alignment between each of the course objectives and associated assessments is presented. As Pellegrino ${ }^{18}$ points out, one type of assessment is not appropriate in all contexts, and when a single assessment is used for multiple purposes this can compromise its ability to accurately reflect student achievement -- assessment tools offer evidence of what students know and reasonable inferences can be drawn based on this evidence. Therefore, several types of assessment were chosen representing both individual achievement (summative) ${ }^{18}$ and assessments to assist student learning (formative). ${ }^{18}$ Two kinds of summative individual assessments will occur in this course. On the first day of the course each student will be presented with a short case to identify ethical dilemma, to name possible course of action, and to evaluate the consequences of actions taken. Then again on the last day of class the same case will be discussed with each student and the same questions will be asked. This will provide students with a measure of progress in the areas of the content. The reflection journals that students will write throughout the semester will also act as a kind of informal summative assessment. Grading will measure a student's ability to recognize an ethical issue and analyze possible courses of action, not a student's personal values or moral beliefs.

\section{Pedagogy}

Literature shows that the pedagogical framework of engineering ethics education has evolved primarily toward utilization of case studies and codes of ethics, in some instances supplemented by an introduction to moral theory. Substantial progress has been made in the development of 
case materials, including high profile and everyday cases. Cases are widely disseminated in textbooks and online.

According to Ohland and Barry ${ }^{11}$ within the literature associated with the Engineering profession, there is much discussion and debate over instruction methods and curriculum incorporation methods. The use of case-based instruction methods appears to be the most common pedagogical method within the engineering ethics education. Research related to professional ethics within the discipline has primarily focused on the assessment of student learning, rather than evaluation of instructional methods and/or curriculum incorporation methods. A limited number of studies have been published that compare two methods of instruction or two methods of curriculum incorporation. ${ }^{11}$

In the widely used engineering ethics text by Harris, he makes the statement that "there is widespread agreement that the best way to teach professional ethics is by using cases." 21 However, a meta-analysis of conference papers conducted by $\mathrm{Haws}^{22}$ identifies an emphasis on codes and theoretical grounding as two other methods of engineering ethics instruction. Likewise, codes and ethical theories that are also discussed extensively in the texts of Harris et al. $^{21}$ and Fleddermann. ${ }^{23}$

My personal experience from attending and observing classes where ethics is taught has led me to the conclusion that it is not sufficient to teach ethics through example alone. One cannot expect that students will be able to understand and adapt to the professional standards and values of the community simply by observing the behavior of professionals. Learning by observation requires interpretation. The rationale and assumptions that underlie behavior are not always obvious. Observational learning, alone, is not an efficient method of communicating critical issues. Based on these arguments this course will be presented through a combination of fundamental theory and case studies.

Having overall the site design of the Engineering Ethics course requires that I determine my teaching philosophy. This, in turn, will help me to shape the course activities and design course materials and allow me to have well-aligned learning goals with the content, the assessments, and the pedagogical principles and practice.

\section{Pedagogical Philosophy}

The pedagogical philosophy used here is intended to educate engineering students for the professional world where they will promote social responsibility and become moral agents. The learning environment provided will engage students in challenging decision making exercises and will encourage students' enthusiasm for life-long learning, competency in the subject, and self-assurance to apply their knowledge in real world settings. This course is open to students of all majors. This is important because the landscape of engineering practice is fairly diverse. The differing levels of engineering knowledge, and moral codes as influenced by cultural backgrounds must be taken into account when fostering critical and analytical thinking. Class information presented must be made meaningful to students by finding points of relevance and intersection with their lives and accounting for different learning styles. Students should not only have an abstract knowledge of ethics but should also develop confidence in making ethical 
decisions and in their own ethical judgment through practice. The instructional methods used will therefore focus on creating an active learning environment for students. Instruction will go beyond lecturing on ethical theories and philosophical terms to discussing and exchanging perspectives. Fundamental theory will be employed to create foundational knowledge but case studies, every day examples, guest speakers, videos, and articles will all be employed to help students to better relate to the information structure and to be able to identify ethical issues, exercise ethical thinking and use ethical judgment - the three learning objectives of this course. This combination of pedagogies and assessment will help students go beyond learning what will help them pass the final exam.

Student debates will be used to minimize the nature and limitations of case studies models and to give the students a more realistic understanding of their purpose and value, and their relationship to the real world. Debate is a form of active learning and can be used as a way to give students experience in "engaging in conducting comprehensive research into the topic, gathering supporting evidence, collaborative learning, delegation of tasks, improving communication skills, and developing leadership and team-skills all at one go". ${ }^{24}$ In class students will represent, as a group, their argument maps and discuss them with the other groups. They will play the role of being an expert briefing a committee. This will help students to improve their skills of critical thinking, collaboration, and problem solving. It will also help to train students in developing skills for resolution of ethical issues and to prepare future's engineers to solve complex ethical and engineering problems. As the course is open to enrollment of all majors in the engineering program and the size of this class is expected to be large, its success will depend on the students' contributions and engagement as part of the interactive teaching style proposed. Besides lectures about the meta-ethical issues listed in the content part of the course design, two different engagement forms will be introduced: class discussion and group work. The discussion approach to instruction, commonly known as discussion teaching, is a pedagogical method that has active learning of students and instructors at its core. ${ }^{25}$ Discussion teaching is organized to (1) create shared responsibility for teaching and learning; (2) honor the voices, experiences, and worldviews of students; (3) promote democratic participation in the teaching/learning dynamics; (4) develop critical thinking and problem solving skills; and (5) create community of learners who work together in the pursuit of knowledge. ${ }^{26}$

The second half of the class will be reserved for discussions about readings that will introduce students to important dimensions of professional ethics. To prepare these discussions, students have to read the texts that are listed for each week in the schedule below, and students have to answer a few questions that will allow them to focus on the readings' central points. Students' job is to read the texts, answer all these questions in about one page, and submit it via Blackboard before class. The idea is that students are best prepared for class discussions when they have already thought at home about the ideas for class. The debate activity and the final project will be team endeavors and will be a way to ease students into activities where they must work with others. Teamwork is an example of one way to create a community-centered learning environment. ${ }^{27}$ In class, we will mainly work in small groups to train ethical argumentation. This training will include three components:

- Analyze case studies or ethical argumentations. Students have to read the material and submit individually an argument or position before coming to class 
- Reconstruct the argumentation, or develop an argumentation based on the material, in groups.

- Represent, as a group, an argument map and discuss it with other groups

\section{Group Project}

Students have to choose one of five offered group projects. The students will separate into five groups and work for two weeks to develop an argument map and prepare to present their case to the rest of the groups in a debate setting. To ensure that students completing design projects take professional responsibility seriously, below are four basic checklists that will help them through an ethical analysis of their project. The checklists ask them:

- to identify stakeholders and their interests;

- to identify the standards or norms they are using to make decisions about a) technological development, b) economic impact, c) safety, d) public health, e) impact on society f) culture impact, i) equity, and j) environmental impacts;

- to assess whether they are adhering to the professional guidelines in the NSPE Code of Ethics;

- to review their project from at least three different ethical perspectives

Other pedagogical activities in this course include:

Reflection - In this course reflective practice is a part of several of the course activities: personal journals; reflection after guest speakers; reflection after watching videos. The purpose of reflection is for students to reinforce what they are learning by thinking about it explicitly. ${ }^{27,14}$ One way of encouraging reflection is for the instructor to challenge students to explain what their thoughts are after these interactions. Students will engage in reflective discussions at the end of the guest presentation and after the movie.

Transfer - According to Svinicki ${ }^{14}$ the ability to use knowledge in multiple contexts is evidence of true understanding. This idea is known as transfer. Providing students with progressively more theory and asking students to apply it in different situations will hopefully encourage the transfer and reinforcement of ethical thinking for resolution of ethical dilemmas from one context to another. Students will be shown how what they have learned in previous lectures and activities can be applied to resolving ethical dilemmas in cases and projects they are currently working on.

Feedback - Students will constantly receive feedback from the instructor on assignments as well as from other students during group activities. According to Pellegrino "Students learn more when they receive feedback about particular qualities of their work, along with advice on what they can do to improve". ${ }^{18}$

\section{Alignment of the learning goals, content, assessment and pedagogy}

In developing a single course approach to engineering ethics, it is important that students have clear course learning goals, a course outline and an understanding that ethics has teachable and testable content (See Appendix Fig. 3). Responsible engineers must be aware of: how their work as engineers will affect people, society, and the environment; the codes of ethics that apply to 
their area of practice: the laws and safety standards and how they should be used; as well as cases and examples of responsible and irresponsible engineering practice. This is factual information, information that can be introduced to students in different ways and tested. Critical reasoning skills can also be taught and tested.

In this paper the course content is aligned with appropriate assessments that will offer evidence of students learning and pedagogical approaches are employed to enable students learning. The content for the engineering ethics course discussed in this document is driven by three primary learning goals: students identifying ethical issues, exercising ethical thinking, and resolving ethical dilemmas. Formative and summative assessment measures were design to highlight what students have learned. Finally the instructional methods used for this course are based on a devotion to creating an active and interactive learning environment for students.

\section{Next Steps}

As this paper was originally developed for a course with the intention to develop it further through research, the next step will be to give assessment information and to have expansion of our knowledge about how students learn moral reasoning and what can improve that. Before incorporating the course into a curriculum, this paper has been sent to knowledge experts in the engineering ethics field for peer review and evaluation of the assessment tool. The results from the survey will be presented on the ASEE conference in June 2011. In the Fall of 2011 further research is planned in collaboration with social psychology researchers at Purdue University that will investigate the relationship between moral reasoning development and personality factors.

As additional research is completed we will be able to frame the study in a manner that would permit disseminating key information that would enable implementation of similar courses in university settings.

\section{Bibliography}

1. ABET.(2000). Criteria for accrediting engineering programs. Baltimore: ABET, Inc.

2. Schinzinger, R. and Martin, M.W., (2000). Introduction to engineering ethics. Boston: McGraw-Hill,(8), 108.

3. Baura, G.D. (2006). Engineering Ethics: An industrial perspective. Boston: Elsevier Academic Press.

4. Stephan, Karl D. (2001) Is Engineering Ethics Optional? IEEE Technology and Society Magazine 20 (4).

5. Tatu, Robin,. (2010). Judgment Calls: History's ethical dilemmas and dark chapters hold lessons for tomorrow's engineers. ASEE Prism, October 2010, pg. 52

6. Educating The Engineer of 2020: Adapting Engineering Education to the New Century, National Academy of Engineering, The National Academies Press, Washington, DC (2005)

7. Barry, B. (2009) Methods of incorporating understanding of professional and ethical responsibility in the engineering curriculum and results from the fundamentals of engineering examination. Dissertation

8. Herkert, J.R. (2002). Continuing and emerging issues in engineering ethics education. The Bridge, 32(2). 
9. Weil, V.(2003). Ethics across the curriculum: Preparing engineering and science faculty to introduce ethics in their teaching. In W. Wulf (Ed.), Emerging technologies and ethical issues in engineering: Papers from a workshop, October, 2003. Washington D.C: National Academic Press.

10. Herkert, J.R. (2000). Engineering Education in the USA: Content, pedagogy and curriculum. European Journal of Engineering education, 25(4).

11. Ohland, M. \& Barry B., (2009) Applied Ethics in the Engineering, Health, Business, and Law Professions: A Comparison. Journal of Engineering Education, October 2009.

12. Pritchard, Michael S., (2010). Teaching Engineering Ethics: A case study approach. Center for the study of Ethics in Society, Western Michigan University.

13. Interview with Tinus (January 10, 2011).

14. Svinicki, M. (2004). Learning and Motivation in the Postsecondary Classroom. Bolton, Massachusetts: Anker Publishing Company.

15. Wiggings \& McTighe Establish Curricular Properties

16. Fink, L. (2003). A Self-Directed Guide to Designing Courses for Signficant Learning. In L. Fink (Ed.), Creating Stifnificant Learning Experiances: An Integrated Approach to Designing College Courses. San Francisco: Jossey-Bass.

17. Shuman, L.J., Sindelar, M.F., et al. (2004). Can our students recognize and resolve ethical dilemmas? Paper presented at the American Society for Engineering Education Annual Conference\& Exposition, Salt Lake City, Utah.

18. Pellegrino, J. W., et al. (2001). Knowing What Students Know: The Science and Design of Educational Assessment. Washington, D.C.: National Academy Press.

19. Pittsburg - Mines Engineering Ethics Rubric, University of Pittsburg and Colorado School of Mines

20. Ramsden, P. (1993). Learning to Teach in Higher Education, Routledge, London.

21. Harris, Charles E., Jr., Michael Pritchard, and Michael J. Rabins .Engineering Ethics: Concepts and Cases. Belmont, CA: Wadsworth, $4^{\text {th }}$ ed., 2008

22. Haws, D. R. (2001). Ethics instructions in engineering education: A (mini) meta-analysis. Journal of Engineering Education, 90(2).

23. Fleddermann, C.B. (2008). Engineering ethics ( $2^{\text {nd }}$ ed.). Upper Saddle River, N.J.: Pearson Education.

24. Christudason, A. (2003). The Debate as a Teaching/Learning Tool. Ideas on Teaching, 1, from http://www.cdtl.nus.edu.sg/Ideas/iot23.htm

25. Christensen, C. R., Garvin, D. A., \& Sweet, A. (Eds.). (1991). Education for judgment: The artistry of discussion leadership. Boston, MA: Harvard Business School Press.

26. Brookfield \& Preskill, (2005). Discussion as a Way of Teaching: Tools and Techniques for Democratic Classroom. Josse Bass Higher and Adult Education

27. Bransford, J. D., et al. (2000). How People Learn: Brain, Mind, Experience, and School. Washington, D.C.:National Academy Press. 


\section{Appendix}

\section{The Assessment Triangle for resolution of ethical dilemmas}

\section{Observation:}

Identified ethical dilemmas

Named possible actions

Evaluated consequences of actions

\section{Interpretation:}

Students fail to see or clearly identify key ethical issues

Students provide no analysis to students cite analogous cases, offer more than one alternative solution, and identify risks for each solution.

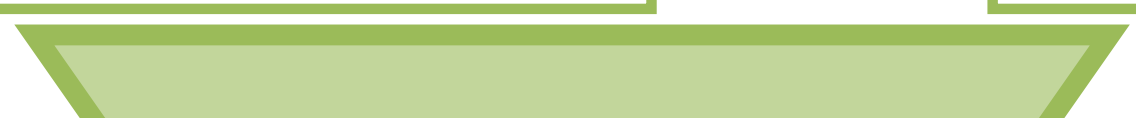

Students to recognize ethical issues

Students to exercise ethical thinking

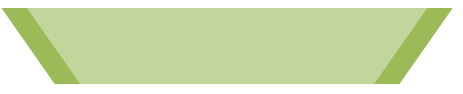

\section{Students to apply ethical judgment}

\section{Cognition:}

Kohlberg stages of moral development

1. Obedience and Punishment orientation orientation

2. Self-interest orientation

3. Interpersonal accord and conformity
4. Authority and Social-order

5. Social contact orientation

6. Universal Ethical Principles
University of Pittsburgh \& Colorado School of Mines rubric matrix

The rubric measures the following five attributes: on a scale of "1 (lowest) through 5 (highest)

Recognition of dilemmas - (1) students fail to see problem; (5) student clearly identifies key ethical issues.

Information - (1) students ignore important facts; (5) students identify unknown facts and use their own expertise to add appropriate information

Analysis - (1) students provide no analysis; (5) students cite analogous cases, offer more than one alternative solution, and identify risks for each solution.

Perspective - (1) students have wondering perspective; (2) students have one perspective; (5) students have global perspective.

Resolution - (1) No resolution, resolution lacks integrity; (5) resolves case thoroughly through clear argumentation and understands consequences of various actions.

Fig.1 Assessment Triangle for Resolution of Ethical Dilemmas 


\section{Learning Goals and Assessments}

\begin{tabular}{|c|c|c|}
\hline Learning Goal & \multicolumn{2}{|l|}{ Assessment } \\
\hline \multirow{2}{*}{$\begin{array}{l}\text { Students will } \\
\text { recognize ethical } \\
\text { issues }\end{array}$} & & \\
\hline & $\begin{array}{l}\text { Task: "One-minute" essay-students will } \\
\text { write a few sentences at the end of a } \\
\text { discussion summarizing its content }\end{array}$ & $\begin{array}{l}\text { Evidence: The instructor will see what the } \\
\text { students caught and helps the students organize } \\
\text { and retain the experience before it begins to fade }\end{array}$ \\
\hline \multirow{2}{*}{$\begin{array}{l}\text { Students will exercise } \\
\text { their ethical thinking }\end{array}$} & \multicolumn{2}{|c|}{ Claim: Students will be able to use their ethical thinking } \\
\hline & $\begin{array}{l}\text { Task: Students are given a short case } \\
\text { to read and ask after to identifying the } \\
\text { ethical dilemma to formulate and } \\
\text { defend a course of action }\end{array}$ & $\begin{array}{l}\text { Evidence: Students will name at least two } \\
\text { possible actions that could be taken in response } \\
\text { to given ethical dilemma }\end{array}$ \\
\hline \multirow{2}{*}{$\begin{array}{l}\text { Students to apply } \\
\text { ethical judgment }\end{array}$} & \multicolumn{2}{|c|}{ Claim: Students will be able to practice ethical judgment } \\
\hline & $\begin{array}{l}\text { Task: Students will be ask to apply } \\
\text { professional, legal, and personal codes } \\
\text { to a case study to identify options and } \\
\text { limits on their actions }\end{array}$ & $\begin{array}{l}\text { Evidence: Students will describe and evaluate } \\
\text { the probable consequences of these actions }\end{array}$ \\
\hline
\end{tabular}

Fig. 2 Learning Goals and Assessments 


\begin{tabular}{|c|c|c|}
\hline & Alignment & \\
\hline $\begin{array}{c}\text { Content (Learning } \\
\text { Goals) }\end{array}$ & Assessment/Task activities & Pedagogy \\
\hline \multirow[t]{3}{*}{$\begin{array}{l}\text { Students will identify } \\
\text { ethical issues }\end{array}$} & $\begin{array}{l}\text { First and last day the same } \\
\text { "One minute essay" }\end{array}$ & Transfer \\
\hline & Journals & Reflection \\
\hline & $\begin{array}{l}\text { Summative and formative } \\
\text { assessment }\end{array}$ & \\
\hline $\begin{array}{l}\text { Students will } \\
\text { exercise their ethical } \\
\text { thinking }\end{array}$ & $\begin{array}{l}\text { Students groups will be } \\
\text { evaluated through the rubric } \\
\text { Formative assessment }\end{array}$ & $\begin{array}{l}\text { Debate } \\
\text { Cooperative learning }\end{array}$ \\
\hline \multirow{3}{*}{$\begin{array}{l}\text { Students to apply ethical } \\
\text { judgment }\end{array}$} & $\begin{array}{l}\text { Guess Speakers } \\
\text { Movie }\end{array}$ & $\begin{array}{l}\text { Active learning } \\
\text { Reflection }\end{array}$ \\
\hline & $\begin{array}{l}\text { Group Project-Students will } \\
\text { work in small groups to prepare } \\
\text { for the debate }\end{array}$ & $\begin{array}{l}\text { Active learning } \\
\text { Group work }\end{array}$ \\
\hline & Final paper & Exploration of the \\
\hline & Evaluated through the rubric & Transfer \\
\hline & $\begin{array}{l}\text { Presentations } \\
\text { Formative assessment }\end{array}$ & $\begin{array}{l}\text { Reflection on the process } \\
\text { Transfer }\end{array}$ \\
\hline
\end{tabular}

Fig. 3 Alignment of the learning goals, content, assessment and pedagogy 